\title{
Muros (in)visiveis: reflexóes sobre o itinerário dos usuários de drogas no Brasil
}

\author{
I ' Lannuzya Veríssimo e Oliveira, ${ }^{2}$ Ardigleusa Alves Coelho, \\ ${ }^{3}$ Pétala Tuani Cândido de Oliveira Salvador, ${ }^{4}$ Claúdia Helena Soares de Morais Freitas I
}

Resumo: Trata-se de um ensaio teórico que objetiva contribuir com o debate sobre o cuidado destinado aos usuários de drogas no Brasil. Assim, problematiza a abordagem proibicionista e segregatória historicamente ofertada a essa população e propõe discussão sobre o uso de drogas na perspectiva da saúde e das ciências sociais/ jurídicas. Além disso, analisa o itinerário dos usuários de drogas, os quais acabam por ocupar "permanentemente" e de forma cíclica espaços públicos que corroboram o agravamento de sua trajetória de vida e adoecimento, ocasionando ônus direto sobre si e sobre sua família, potencializando a segregação social e redesenhando os manicômios, as penitenciárias e as ruas. São revisitadas algumas contribuições sociológicas e antropológicas de Erving Goffman, que oferecem chaves de interpretação para o entendimento dos estigmas que permeiam os usuários de drogas, sobretudo após a inclusão destes em instituiçôes totais. As reflexóes propostas ressaltam a necessidade de consolidar as estratégias de reduçáo de danos como ferramenta de cuidado ético e integral a esta clientela.

> Palavras-chave: usuários de drogas; prisões; hospitais psiquiátricos; população de rua.

\author{
${ }^{1}$ Escola de Saúde, Universidade \\ Federal do Rio Grande do Norte. \\ Natal-RN, Brasil (lannuzyacg@ \\ hotmail.com). \\ ORCID: 0000-0002-6881-898X \\ 2 Departamento de Enfermagem, \\ Universidade Estadual da \\ Paraíba. Campina Grande-PB \\ (ardigleusacoelho@gmail.com). \\ ORCID: 0000-0001-8869-3793 \\ ${ }^{3}$ Escola de Saúde, Universidade \\ Federal do Rio Grande do Norte. \\ Natal-RN, Brasil (petalatuani@ \\ hotmail.com). \\ ORCID: 0000-0002-3208-6270 \\ ${ }^{4}$ Centro de Ciências da Saúde, \\ Universidade Federal da Paraíba. \\ João Pessoa-PB (chsmfreitas@ \\ hotmail.com) \\ ORCID: 0000-0003-0265-5396
}

Recebido em: 04/10/2018 Revisado em: 05/07/2019 Aprovado em: 03/09/2019 


\section{Introdução}

O uso de substâncias psicoativas (SPA) ou drogas está presente desde os primórdios da humanidade como uma permanente manifestação, relacionado a motivaçóes religiosas, sociais, culturais e medicinais, o que remonta a um comportamento milenar de utilizar plantas e substratos de origem vegetal e animal para produzir alteraçóes no estado de consciência, o que durante muitos séculos não apresentou maiores ameaças à sociedade constituída, pois geralmente se dava no bojo de rituais coletivos ou orientado por objetivos que a sociedade reconhecia como expressão de seus próprios valores (GABATZ et al., 2013; RYBCA; NASCIMENTO; GUZZO, 2018).

A partir do século XVI, com as Grandes Navegaçôes, esse panorama começou a mudar, quando os europeus tiveram contato com uma diversidade de produtos, entre eles as SPA. Nesse contexto, a resistência cultural ao processo de colonização assumido por algumas dessas substâncias fez com que, inicialmente, seu uso pelos povos nativos fosse violentamente reprimido pelos colonizadores, como foi o caso do ópio na Ásia e da folha de coca na América Latina (RYBCA; NASCIMENTO; GUZZO, 2018; TORCATO; RIBEIRO, 2015).

Todavia, a partir de meados do século XX, com o desenvolvimento e a expansão global do capitalismo, mudanças e transformaçôes sociais nos padrôes de produção - associados à migraçáo do campo para as cidades, ao advento da ciência e tecnologia e à globalização - ampliaram os significados atribuídos ao uso das drogas, os quais assumem também díspares dimensóes e formas de consumo: a de mercadoria, como pontos de ligação entre os componentes jurídico, econômico e fiscal; a dimensão lúdica e terapêutica, como fonte de desinibição favorecedora do convívio social, como instrumento de tratamento médico; e, por último, as dimensôes de objeto e de origem do crime (FOUCAULT, 1978; PETUCO, 2017).

Ainda que coexistam distintas dimensões acerca do uso das drogas na atualidade, a abordagem junto àqueles que as consomem é preponderantemente proibicionista $\mathrm{e}$ segregatória, pautada em discursos médico-sanitários e jurídicos (PETUCO, 2017).

Com a popularização do consumo de drogas no contexto sociocultural de cada nação, uma série de desdobramentos e impactos sociais - tais como relatos de overdoses, complicaçôes crônicas à saúde e, sobretudo, o desregramento das condutas sociais necessárias ao correto funcionamento do capitalismo - fomentou o fortalecimento de práticas proibicionistas, usualmente conhecidas como "a guerra mundial contra as 
drogas" (FIORE, 2012; NETO et al., 2016). E, ainda que estratégias proibicionistas tenham sido aplicadas previamente em vários contextos socioculturais, foi em 1961, na Convenção Única sobre Entorpecentes, defendida, patrocinada e sediada pelos Estados Unidos, que o proibicionismo se consolida e se difunde para outros países, dentre eles o Brasil, enquanto prática de intervenção do Estado em relação a determinado conjunto de substâncias. Assim, várias naçôes se comprometeram a combater o "flagelo das drogas" e, para tanto, a punir quem as produzisse, vendesse ou consumisse (FIORE, 2012; RYBCA; NASCIMENTO; GUZZO, 2018).

Assim, ancorando-se na autoridade do saber médico, processo este conhecido como a medicalização da sociedade e inscrito em um plano da soberania jurídica normatizadora, o consumo de drogas passa a ser observado também como uma questão de saúde pública, mais especificamente, de saúde mental (VARGAS; CAMPOS, 2019). E classificado em uso, no qual o consumo de substâncias possui caráter esporádico ou episódico; abuso ou uso nocivo, quando o consumo destas substâncias está associado a algum tipo de prejuízo (biológico, psicológico ou social); e por fim, dependência, como o consumo sem controle (BRASIL, 2013). É válido ressaltar que, para além da dificuldade de estabelecer uma fronteira clara entre uso, abuso e dependência, o discurso essencialmente moralizante e os estigmas que permeiam o uso de drogas tendem a caracterizar, de forma apressada e equivocada, quaisquer usuários de drogas como "doentes mentais".

Segundo dados do Relatório Mundial sobre Drogas da Organização das Naçóes Unidas (ONU), o índice mundial de transtornos mentais relacionados ao consumo de drogas tem aumentado significativamente nas últimas décadas, tendo alcançado em 2015 aproximadamente 29,5 milhóes de pessoas (UNODC, 2017). No Brasil, de acordo com o Observatório Brasileiro de Informaçóes sobre Drogas (OBID), 52\% da população brasileira já fizeram uso nocivo de SPA, com destaque para o álcool, seguido da maconha e da cocaína (BRASIL, 2014).

Se o uso de drogas é atualmente observado pelo viés da "saúde", ou, mais precisamente, da doença, é importante contextualizar os avanços e desafios que perpassam as políticas de saúde mental e de álcool e outras drogas no contexto brasileiro (VARGAS; CAMPOS, 2019). Em meados do século XIX, mudanças político-ético-filosóficas germinadas na Europa resultaram na contestação das internaçôes psiquiátricas, que passaram a ser consideradas como uma forma de tratamento obsoleta, o que subsidiou o Movimento de Reforma Psiquiátrica, que no 
Brasil adveio concomitantemente ao processo de redemocratização ocorrido a partir da década de 1980. Tal movimento preconiza a substituição do modelo manicomial por uma rede de serviços territoriais de atenção psicossocial e de base comunitária (AMARAL et al., 2018).

Segundo Penido (2013), o movimento de Reforma Psiquiátrica brasileira iniciado no bojo da Reforma Sanitária compartilha os princípios comuns para a reorientação do modelo de atenção, a saber: a territorialização, a noção ampliada do processo saúdedoença, a integralidade e a intersetorialidade. Deste modo, as pessoas com transtornos mentais, dentre eles os "toxicômanos"/usuários/dependentes de SPA, devem ser cuidados em serviços substitutivos, com destaque para os Centros de Atenção Psicossocial (CAPS), que devem atuar de forma articulada a outros dispositivos assistenciais em Saúde Mental (ambulatórios, leitos em hospital-geral, hospitais-dia) e da rede básica de saúde (Unidades Básicas de Saúde etc.) (BRASIL, 2013).

A configuração do tratamento também deve constituir um elo terapêutico com as Equipes de Estratégia de Saúde da Família (ESF) e os Núcleos Ampliados de Saúde da Família e Atenção Básica (NASF-AB), articulados aos demais dispositivos de suporte social existentes nas comunidades. Assim, seriam formadas redes flexíveis de cuidados, regidas pelos princípios de cidadania dos usuários e pautados por uma política de reduçâo de danos, a qual transfere o escopo das ações das drogas para os indivíduos, propondo-se a assistência com foco na Redução de Danos (BRASIL, 2013; 2015).

No entanto, o Ministério da Saúde publicou a Resolução no 32, de 14 de dezembro de 2017, a qual estabelece as diretrizes para o fortalecimento da Rede de Atenção Psicossocial (RAPS), mas insere os hospitais psiquiátricos nessa rede, bem como estimula o fortalecimento das Comunidades Terapêuticas através do financiamento, o que contraria a proposta antimanicomial até então vigente (BRASIL, 2017b). Mais recentemente, o Decreto no 9.761, de 11 de abril de 2019, aprovou a Política Nacional sobre Drogas, que, embora seja muito recente para permitir a análise de seus impactos, suscita preocupaçôes ao apresentar a abstinência como meta primordial da assistência aos usuários de drogas. Assim, no Brasil, o cuidado com os usuários de drogas esbarra nas controvérsias entre o proibicionismo e o antiproibicionismo no contexto jurídico; a assistência asilar e psicossocial no campo da Saúde/Assistência social (TEIXEIRA et al., 2017); e as limitaçôes da compreensão do uso de drogas apenas sob uma perspectiva meramente fisiológica (JORGE et al., 2018; TAKAHARA et al., 2017). 
Mediante o exposto, este artigo objetiva contribuir com o debate sobre o cuidado destinado aos usuários de drogas no Brasil. Ressalta a indissociabilidade das discussões sobre o uso de drogas no campo da saúde e das ciências sociais/jurídicas. Propóe uma reflexão sobre o itinerário dos usuários de drogas no Brasil, os quais acabam por ocupar "permanentemente" e de forma cíclica espaços públicos que corroboram o agravamento de sua trajetória de vida e adoecimento, ocasionando ônus direto sobre si, sobre a família, potencializando a segregação social e redesenhando os manicômios, as penitenciárias e as ruas (RAUPP; ADORNO, 2015).

Trata-se de um ensaio teórico que discute a interlocução entre os estigmas e instituiçôes totais teorizadas por Goffman $(2017 ; 2015)$ na construção dos muros visíveis e invisíveis que cerceiam os usuários de drogas, bem como busca elucidar as estratégias de redução de danos enquanto ferramentas para transpor tais muros.

\section{Consideraçôes sobre os "muros" teorizados por Goffman}

Entre os anos de 1955 e 1956, Erving Goffman realizou uma pesquisa de campo em um hospital americano, na qual buscou conhecer o mundo social do internado em um hospital. Tal imersão antropológica culminou com a definição das Instituiçôes Totais, que consistem em "um local de residência e de trabalho onde um grande número de indivíduos com situação semelhante, separados da sociedade mais ampla por um período considerável de tempo, levam uma vida fechada e formalmente administrada" (GOFFMAN, 2015, p. 11).

Este autor categorizou as instituiçôes totais de acordo com a sua finalidade, a saber:

I- cuidar de pessoas que são consideradas incapazes e inofensivas;

II- cuidar de pessoas consideradas incapazes de cuidar de si mesmas e que são também uma ameaça não intencional para a comunidade;

III- proteger a comunidade contra ameaças e perigos intencionais, sem se importar muito com o bem-estar das pessoas segregadas;

IV- erigidas com a intenção de realizar de um modo mais adequado alguma tarefa instrumental;

V- servir de refúgio do mundo, que também podem servir como locais de instrução para religiosos (GOFFMAN, 2015).

Apesar de apresentarem distintas finalidades, tais instituiçóes possuem em comum o caráter segregátorio dos internos e a perda da subjetividade e individualidade dos 
mesmos através uma rotina rígida, obrigatória e padronizada. Os muros visíveis que cercam as instituiçóes demonstram aos internos que o "ir e vir" depende da permissão de outros.

Após longas internaçôes, o indivíduo percebe que a instituição total pela qual passou deixou marcas indeléveis em sua vida, que, dependendo do estabelecimento onde esteve internado, podem causar-lhe um certo orgulho (escolas de elite, religiosas e militares) ou podem representar um estigma instransponível, os "muros invisíveis" (prisóes, hospitais psiquiátricos) (GOFFMAN, 2015).

Na próxima seção, serão apresentados os muros (in)visíveis que cercam os usuários de álcool e outras drogas no contexto brasileiro.

\section{Muros (in)visíveis (manicômios)}

Historicamente, têm-se construído lugares de exclusão social destinados a todos aqueles considerados lúpens sociais (indesejáveis), a saber: leprosos, sifilíticos, aleijados, mendigos, alcoolistas e loucos. E, mesmo que no século XVII a loucura passe a ser compreendida como doença, passível de receber um tratamento humanizado diferenciado dos demais "indesejáveis", as pessoas com transtornos mentais permaneceram confinadas, durante séculos, em outro espaço de segregação: os manicômios (BOLONHEIS-RAMOS; BOARINI, 2015).

Prioritariamente com o propósito de preservar os padróes sociais estabelecidos, os manicômios funcionavam como espaços de contenção comportamental de tudo aquilo que não se encontrava na esfera do aceitável. Assim, quaisquer comportamentos inadequados não eram desculpáveis nem mesmo pela loucura; de modo que os "mal comportados" recebiam a prisão pura e simples, como forma de alcançar a uniformização social e moral (FOUCAULT; 1978).

A uniformização à qual se refere Foucault acontece nas Instituições Totais, a saber: manicômios, prisôes e conventos, nas quais o "internado" passa a cumprir rígidas regras institucionais, o que implica a "mortificação do eu", a qual perdura para além do período de confinamento, conforme teoriza Goffman (2015). Destaca-se também que a permanência em manicômios (ou ainda em prisôes) está inapelavelmente imbricada à construção de estigmas sociais. Por estigma compreende-se um atributo profundamente depreciativo pelo qual um indivíduo é reconhecido e, por vezes, reduzido. 
Independentemente de qual seja a origem dos estigmas - seja por deformidades físicas, por culpas de caráter individual (percebidas como vontade fraca, paixóes tirânicas ou não naturais, crenças falsas e rígidas, desonestidade, inferidas a partir de relatos conhecidos de, por exemplo, distúrbio mental, prisão, vício, alcoolismo, homossexualidade, desemprego, tentativas de suicídio e comportamento político radical) ou por estigmas tribais de raça, nação e religião -, resultam nas mesmas características sociológicas: um indivíduo que poderia ter sido facilmente recebido na relação social cotidiana possui um traço que se pode impor a atenção e afastar aqueles que ele encontra, capaz de destruir a possibilidade de atenção para outros atributos seus (GOFFMAN, 2017).

No Brasil, apesar da desinstitucionalização como eixo norteador referendado pela legislação entre os anos de 2001 e 2017, dos inegáveis avanços da Reforma Psiquiátrica Brasileira e da estruturação da RAPS, estudos apontam que muitos são os entraves para o cuidado de usuários de álcool e/ou outras drogas no âmbito do Sistema Único de Saúde (SUS), os quais corroboram a manutenção de longas internações em instituiçôes psiquiátricas em decorrência da dependência de drogas (GABATZ et al., 2013; COSTA; RONZANI; COLUGNATI, 2017).

Acrescente-se que a rede de criminalização das drogas criou um circuito discursivo vicioso e hermético em que o usuário de drogas, embora um "doente", passa a ser também o um agente promotor do tráfico de drogas, logo, um agente da rede criminosa, o que justifica o cerceamento de sua liberdade através da internação compulsória (AZEVEDO; SOUZA, 2017). Nesse contexto, destacamse as comunidades terapêuticas, inclusive as de modalidade compulsória, com financiamento público, que mantêm o caráter segregatório, higienista, oposto às estratégias de Redução de Danos e com altas taxas de recaídas por parte dos usuários (BOLONHEIS-RAMOS; BOARINI, 2015; PEREIRA et.al., 2017).

A busca pela internação em instituições psiquiátricas acontece, na maioria das vezes, por exigências dos familiares, ou frente a situaçóes de risco que envolvem familiares, trabalho, problemas financeiros, legais e rompimento de relacionamento afetivo (GABATZ et al., 2013).

Torna-se relevante ponderar que, se por um lado o advento e promulgação da Lei no 10216/2001 garantiu a efetiva substituição progressiva dos leitos psiquiátricos e da internação para serviços substitutivos de portas abertas; por outro, o aumento do uso do crack na segunda década dos anos 2000 ressuscitou o fenômeno das internaçóes 
compulsórias, que responde aos sentimentos de medo, insegurança e impotência da sociedade, configurando no usuário de drogas, sobretudo nos de crack, a condição de infrator e de perigo social (LERMEN; DATORA; CAPRA-RAMOS, 2014). Não obstante, é mister considerar a pouca resolutividade das intervenções e dos procedimentos realizados em internaçôes para desintoxicação, pois os usuários dificilmente conseguem manter-se em abstinência após a alta, o que corrobora altas taxas de reinternação (COSTA; RONZANI; COLUGNATI, 2017).

A literatura sinaliza que as internaçôes psiquiátricas não alcançam resultados satisfatórios, pois acentuam a segregação social dos usuários e reforçam os estereótipos, os estigmas e os preconceitos que permeiam o uso de drogas. O tratamento baseado na medicalização excessiva em detrimento da integralidade do cuidado, da humanização do atendimento e da ausência de corresponsabilização dos sujeitos envolvidos no processo terapêutico também contribui com o fracasso das propostas terapêuticas (COSTA; RONZANI; COLUGNATI, 2017).

Ressalta-se ainda que o uso de drogas, no geral, inicia-se precocemente, o que corrobora o baixo aproveitamento escolar e, consequentemente, dificulta a inserção no mercado de trabalho, o que é capaz de acentuar a marginalização vivenciada pelo usuário de drogas (MOMBELLI; MARCON; COSTA, 2010) e subsidiar a continuidade de seu itinerário em outros espaços "não terapêuticos", a exemplo das penitenciárias.

\section{Muros (in)visíveis (penitenciárias)}

Em meados do século XVI, com o surgimento da sociedade industrial e o desenvolvimento do capitalismo monopolista, as condiçôes de pobreza e miséria se expandiram por toda a Europa. Nesse contexto proliferaram os manicômios e as prisôes, posteriormente difundidos para os demais continentes, que atendiam às necessidades da elite dominante, no que se refere à máo de obra barata para o desenvolvimento industrial emergente e "limpeza" das cidades daqueles compreendidos como indesejáveis sociais (FOUCAULT, 1978). Assim, o caráter higienista e punitivo das grandes internaçôes, preponderantemente contrário à ressocialização social, é observado até a atualidade na conjuntura dos usuários de drogas.

Ressalta-se ainda que o caráter higienista e punitivo de tais internaçóes se fortalece a partir das crises e questionamentos acerca do Welfare State/ Estado do 
Bem-Estar Social, assim o Estado Penal encontrou espaço para consolidar-se e tornou-se símbolo do novo modelo de gestão, em que os princípios da igualdade e bem-estar são sopesados com o da punibilidade, sendo que o último se sobrepóe aos outros. (KERSTENETZKY, 2011; WACQUANT, 2014).

Desse modo, nota-se que a "guerra contra pobreza" foi substituída por uma "guerra contra os pobres", travestida ainda de "guerra contra as drogas", o que transformou determinados segmentos de usuários de drogas em "culpados" de grandes males sociais, passíveis de punição, encarceramento e exclusão em muros (in) visíveis (WACQUANT, 2014). Outrossim, a criminalidade no país está fortemente vinculada à dependência química, apontando que os crimes mais comuns (furtos, roubos e tráfico de drogas) são frequentemente cometidos para prover o consumo pessoal de drogas (BRASIL, 2015). Portanto, apesar de existir situaçôes em que o contato com as drogas deu-se apenas após a inserção no ambiente prisional, sabe-se que, na maioria das vezes, o envolvimento com drogas precede o encarceramento.

Frente a essa tragédia, a sociedade pede como resposta açôes policiais com maior truculência, redução da maioridade penal e encarceramento em massa. Medidas que contribuem para a repetiçấo do ciclo da violência, pois náo atuam na raiz do problema, que é melhorar as condiçôes de vida dos indivíduos com maior risco de serem vítimas ou executores de violência (CERQUEIRA et al., 2017).

Em estudo desenvolvido por Nicolau et al. (2012) com populaçáo privada de liberdade do Ceará, a maior parte dos participantes (61,7\%) relatam uso de drogas antes do aprisionamento, parceiros íntimos com histórico de dependência química $(55,8 \%)$ e o aprisionamento causado por tráficos de drogas $(52,9 \%)$. Em outro estudo realizado em Porto Alegre com pacientes psiquiátricos que já tiveram passagem por instituiçóes prisionais, a porcentagem de uso de drogas no cárcere chegou a 40\% (LERMEN; DATORA; CAPRA-RAMOS, 2014). Ademais, tornase válido considerar que o ambiente reconhecidamente insalubre do cárcere favorece o adoecimento físico e mental dos indivíduos e potencializa a ansiedade dos internos para utilizar drogas lícitas e ilícitas (OLIVEIRA et al., 2013).

Sabe-se, entretanto, que o aparato de segurança existente nas prisóes em cumprimento à legislação jurídica no país não permite o acesso de álcool e/ou outras drogas nas prisóes, mas, ao que parece, há um certo acordo tácito sobre os benefícios do uso de "certa quantidade" de drogas nas prisóes, com a justificativa de "acalmar 
os ânimos" dos internos e permitir o funcionamento institucional (LERMEN; DATORA; CAPRA-RAMOS, 2014).

No que tange ao tratamento de dependentes químicos no âmbito prisional, o Plano Nacional de Saúde do Sistema Penitenciário (PNSSP) de 2003 previa atenção às situaçôes de grave prejuízo à saúde decorrente do uso de álcool e drogas, na perspectiva da reduçấo de danos (BRASIL, 2004). Porém, torna-se válido refletir que, se o uso de drogas na prisão é uma situação velada e negada, acredita-se que os presidiários não recebam atendimento em saúde mental adequado às premissas da redução de danos, porque os dados sobre o número de usuários de drogas nas prisôes e os tipos de drogas utilizados são, muito provavelmente, subnotificados.

Em janeiro de 2014, instituiu-se a Política Nacional de Atenção Integral à Saúde das Pessoas Privadas de Liberdade no Sistema Prisional (PNAISP), que reformulou a composição mínima das equipes de saúde no sistema prisional (ESP) e ampliou o escopo da atuação no sistema prisional com a inclusão de profissionais para atuar especificamente com saúde mental (BRASIL, 2014).

No entanto, estudos apontam que são muitos os entraves para a efetiva implantação e execução da PNAISP, tais como: a atenção à saúde da população feita sob ótica reducionista; a assistência centrada na figura do profissional médico; escassas açôes de promoção da saúde; além de dificuldades metodológicas e operacionais para implantação efetiva de atividades das unidades de saúde nas instituições prisionais (BARBOSA; COSTA; CELINO, 2015; COSTA et al., 2014).

Oliveira et al. (2013) apontam para as dificuldades de ressocialização após o aprisionamento que repercutem diretamente na reincidência criminal e/ou no aumento da situação de população de rua. Esta população, em sua maioria, é usuária de drogas, com presumível agravamento do seu quadro psicopatológico, ocasionando uma "realimentação" do ciclo em que os usuários transitam: ruas, prisôes, manicômios.

Nesta condição cíclica, observa-se que os grupos historicamente mais vulneráveis e marginalizados permanecem ocupando os espaços de segregação/controle social, justificados e rotulados com o selo do uso de drogas, perscrutados por encerrar traços históricos dos desvios e transgressóes das normas e estatutos sociais (WACQUANT, 2014.) Tal qual apontam os dados dos Infopen, em que que $64 \%$ da populaçáo prisional são compostos por pessoas negras. $\mathrm{Na}$ populaçáo brasileira acima de 18 anos, em 2015, a parcela negra representa 53\%, indicando a sobrerrepresentação deste grupo populacional no sistema prisional (BRASIL, 2017a). 
Achados que mostram a notória discriminação racial como resíduo do período de escravidão, e demonstram a desigualdade eminente e as diferenças de oportunidades apresentadas para esse grupo marginalizado pela sociedade. Destarte, a criminalização das drogas configura-se em sua gênese na criminalização da pobreza e na licença para "limpeza social" (NETO et al., 2016).

\section{Muros (in)visíveis (ruas)}

A hegemonia neoliberal, a urbanização acelerada, a internacionalização da economia, entre outros fenômenos que caracterizam a nova ordem mundial, têm provocado, entre outros efeitos, um aumento significativo da exclusão social. Nesse contexto, há o crescimento da População em Situação de Rua (PAIVA et al., 2016; ZUIM; TRAJMAN, 2018).

É válido ressaltar que, se por um lado alguns adentraram no vício após vivenciarem situação de rua, para outros viver nas ruas é consequência da fragmentação familiar, do desemprego e das perdas econômicas associadas à dependência de drogas (COSTA et al., 2015). Mas, independentemente de qual seja o início desse itinerário, percebese, na conjuntura atual, que o "Estado do Bem-Estar Social" transcende para um "Estado Penal” (PAIVA et al., 2016; WACQUANT, 2014).

Segundo dados da Pesquisa Nacional sobre População em Situação de Rua realizada entre os meses de agosto de 2007 e março de 2008, em municípios com mais de 300.000 habitantes no Brasil, identificou-se, aproximadamente, 50.000 pessoas adultas em situação de rua. As principais razóes alegadas por aquelas pessoas foram alcoolismo/drogas (35,5\%); desemprego (29,5\%); e desavenças com familiares (29,1\%) (BRASIL, 2008). Acrescente-se o significativo número de crianças e adolescentes em situação de rua no Brasil, que ultrapassa 23.973 (CARDOSO; BECKER, 2014).

Deste modo, existem dois fenômenos distintos que se interligam, considerados graves problemas de saúde pública: o viver nas ruas e o uso de drogas. Por um lado, o uso nocivo de drogas é um dos principais fatores que predispóem os indivíduos a vivenciarem a situação de rua; por outro, as condiçôes insalubres e de desamparo nas ruas favorecem a dependência. E, por sua vez, os dois fenômenos estão associados à marginalidade e à sedimentação de estigmas e preconceitos contra essas populaçóes (PAIVA et al., 2016). 
Todavia, a existência de população de rua associada ao uso de drogas só ganhou notoriedade nacional com o aparecimento do crack no Brasil, quando foi dada grande ênfase na mídia ao surgimento da Cracolândia, localizada na região central do município de São Paulo, situada próxima a prédios históricos e ruas de intenso movimento comercial, onde transitavam muitos usuários e vendedores de crack (RAUPP; ADORNO, 2015).

Passadas mais de duas décadas desde o surgimento da Cracolândia de São Paulo e de espaços semelhantes em outras metrópoles, é notória a sua permanência como palcos de enfrentamentos e foco de processos nos quais as políticas sanitárias, com o objetivo de expulsar e internar compulsoriamente os usuários se alinham a outras forças, como a especulação imobiliária e questôes políticas, que objetivam esconder e punir aqueles que não deveriam ocupar espaços públicos, repetindo um ciclo secular de exclusão e ineficiência das políticas públicas no tocante à promoção de cidadania e qualidade de vida da sociedade no geral (RAUPP; ADORNO, 2015).

A prática policialesca ou de coerção reforça as representações estigmatizantes dos usuários de drogas, além de agravar as condiçóes de saúde desse grupo, propicia o surgimento de tensões e violência entre si e, ainda, com outros grupos historicamente presentes nesses espaços, como pedintes e profissionais do sexo (SOUZA; CARVALHO, 2014).

Ressalta-se que a prática da coerção dificulta, ou mesmo impossibilita, a criação de vínculo com os profissionais de saúde, elemento considerado premissa para o desenvolvimento de práticas terapêuticas em saúde mental e para redução de danos (BRASIL, 2013).

\section{A estratégia da redução de danos: rompendo os muros}

Historicamente, as políticas públicas de saúde permitiram a existência de uma lacuna no tocante aos usuários de drogas, ao delegar a responsabilidade com esta clientela à Justiça, à segurança pública e às associaçóes religiosas. Tal atitude corrobora a premissa de que qualquer usuário de drogas é um “doente mental” e, consequentemente, incapaz de responder por suas escolhas, corroborando modelos de tratamento tradicionais, convergentes para o uso imperativo da abstinência. Como estratégia alternativa ao modelo proibicionista para o enfrentamento de questôes relacionadas ao consumo de álcool e outras drogas emerge o modelo da Redução de Danos (RD) (LERMEN; DATORA; CAPRA-RAMOS, 2014). 
As estratégias de RD são utilizadas desde a década de 1940 na Inglaterra; na Holanda foram amplamente difundidas em meados da década de 1970; mas no Brasil só começaram a ser adotadas como estratégia de saúde pública no ano de 1989, quando os altos índices de transmissão de HIV estavam relacionados ao uso indevido de drogas injetáveis (BRASIL, 2013). Pensada inicialmente como uma estratégia de prevenção ao HIV/AIDS entre usuários de drogas injetáveis Programa de Troca de Seringas (PTSs) - a RD foi ao longo dos anos se tornando uma estratégia de produção de saúde alternativa às estratégias pautadas na lógica da abstinência, incluindo a diversidade de demandas e ampliando as ofertas em saúde para a população de usuários de drogas (BRASIL, 2013).

A RD, no contexto do uso de drogas, consiste em um conjunto de medidas em saúde que visam minimizar as consequências adversas provenientes do uso e abuso de SPA, cujo princípio fundamental é o respeito à liberdade de escolha do indivíduo e o acesso aos serviços de saúde (LERMEN; DATORA; CAPRA-RAMOS, 2014). Assim, na perspectiva da RD, torna-se fundamental a valorização do desejo e das possibilidades dos sujeitos, de modo que os profissionais de saúde devem nortear suas práticas no diálogo e na negociação (BRASIL, 2013). Considera-se que nem todos desejam parar de usar drogas, mas é direito de todos receber alguma forma de cuidado mediante a sua aceitação (SOUZA; CARVALHO, 2014).

No tocante à população de rua, mediante a perspectiva da RD, surgiram os Consultórios de Rua vinculados ao Departamento de Saúde Mental (atualmente chamados Consultórios na Rua, vinculados à Atenção Básica) que ofertam serviços na modalidade de atendimento extramuros e promovem acessibilidade aos serviços de saúde, assistência integral aos usuários de rua e promoção de laços sociais com enfoque intersetorial (KAMI et al., 2016).

$\mathrm{O}$ processo de ampliação e definição da $\mathrm{RD}$ como uma proposta ética, clínica e política para a política pública brasileira de saúde de álcool e outras drogas enfrenta grande dificuldade para superar o arquétipo da abstinência, que, por sua vez, se pauta na articulação entre Justiça, psiquiatria e moral (BOLONHEIS-RAMOS; BOARINI, 2015).

Os entraves perpassam também pela fragmentação da RAPS e deficiência na formação dos profissionais e gestores de saúde, cuja prática privilegia o modelo biomédico em detrimento da integralidade e da humanização (SOUZA; CARVALHO, 2014). Porém, para além dos entraves, defende-se a RD como um 
dos caminhos para romper os muros (in)visíveis que cercam os usuários de álcool e drogas, favorecendo a ressocialização, a melhoria da qualidade de vida e o resgate da cidadania desses sujeitos (Figura 1).

Figura 1: Itinerário dos usuários de álcool e outras drogas

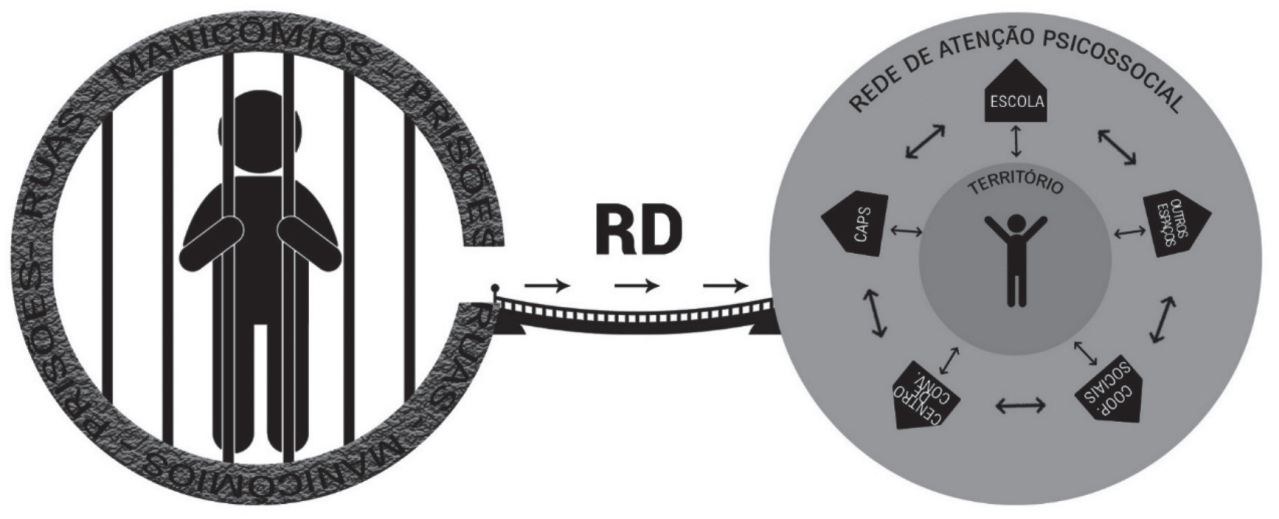

Assim, tal qual apresenta a figura acima, a RD configura-se como uma possibilidade de tratamento adequado e humanizado aos usuários de álcool e drogas, transpondo a coerção e a segregação social, ao inserir este usuário em uma rede de cuidado de base territorial e comunitária. Não obstante, é válido ressaltar que a reflexão aqui proposta não objetiva extrapolar as possibilidades da RD, e que seria ingênuo compreendê-la como capaz de romper com os elementos que ancoram historicamente as estruturas sociais vigentes. Mas crê-se que, ao focar suas intervençôes no campo dos direitos humanos, a partir da singularidade de cada sujeito envolvido, é capaz de promover transformaçóes culturais, sociais e educacionais positivas para os usuários de drogas e para sociedade no geral (SANTOS; QUEIROZ, 2016).

\section{Considerações finais}

Ao longo dos anos, os usuários de álcool e/ou outras drogas ocuparam, no imaginário social, um espaço de exclusão e marginalidade, acentuado com a difusão das cracolândias e a cobertura midiática. Associe-se a isto o fato da repressão ao uso de drogas, que tornou essa problemática uma responsabilidade policial, em detrimento da responsabilidade sanitária. 
Deste modo, compreende-se o motivo pelo qual o "tratamento" de usuários de drogas deu-se sob a égide da coerção, imposição e punição. Nesta perspectiva, torna-se incapaz de alcançar o objetivo a que se propôs, a saber: a abstinência. $\mathrm{Ou}$ ainda, que a elaboração de novos critérios diagnósticos proporcionou um aumento no número de casos passíveis de intervenção, conferindo o estatuto médico ao que antes era tratado de modo policial, mas ambas as condutas sem levar em conta a singularidade dos sujeitos.

Ademais, a coerção subsidiou ainda mais o afasta mento entre usuários e sociedade, permitindo a manutenção do ciclo em que usuários de drogas (sobretudo os de baixo nível socioeconômico) percorrem ruas, prisóes e manicômios sem nenhuma resolutividade para suas demandas, como um calvário para o supliciamento de suas lutas e sobrevivência com o álcool e/ou outras drogas.

Neste contexto, colocar em discussão aspectos socioantropológicos que permeiam o itinerário de usuários de álcool e drogas possibilita a reflexão ampliada sobre a temática, e reforça o papel das estratégias de RD como uma ferramenta de cuidado ético e integral a esta clientela. Sobretudo, mediante a atual conjuntura política brasileira, que sinaliza retrocessos na implementaçáo de políticas intersetoriais para o combate as iniquidades sociais, bem como apregoa um discurso contrário aos direitos humanos. ${ }^{1}$

\section{Referências}

AMARAL, C. E. M. et al. Apoio matricial em Saúde Mental na atenção básica: efeitos na compreensão e manejo por parte de agentes comunitários de saúde. Interface (Botucatu), v. 22, n. 66, p. 801-812, set. 2018.

AZEVEDO, A. O.; SOUZA, T. P. Internação compulsória de pessoas em uso de drogas e a Contrarreforma Psiquiátrica Brasileira. Physis, Rio de Janeiro, v. 27, n. 3, p. 491-510, jul. 2017. BARBOSA, M. L.; COSTA, G. M. C.; CELINO, S. D. M. Saúde e doença: concepçōes e necessidades percebidas no sistema penitenciário. Rev enferm UFPE, v. 9, supl. 1, p. 261-70, 2015. BOLONHEIS-RAMOS, R. C. M.; BOARINI, M. L. Comunidades terapêuticas: "novas" perspectivas e propostas higienistas. Hist. cienc. saude-Manguinhos, Rio de Janeiro, v. 22, n. 4, p. 1231-1248, dez. 2015.

BRASIL. Ministério da Saúde. Pesquisa Nacional sobre o Uso de Crack 2014. Observatório Brasileiro de Informaçóes sobre Drogas (OBID). Brasília: Ministério da Saúde, 2014.

. Portaria Interministerial no 1777, de 9 de novembro de 2003. Plano Nacional de Saúde no Sistema Penitenciário. Brasília: Ministério da Saúde, 2004. 
- Portaria Interministerial $n^{o} 1$, de 2 de janeiro de 2014.Política Nacional de Atenção Integral à Saúde das Pessoas Privadas de Liberdade no Sistema Prisional (PNAISP). Brasília: Ministério da Saúde, 2014.

. Ministério da Saúde. Caminhos do cuidado: caderno do tutor. Brasília: Ministério da Saúde, 2013.

_. Ministério da Justiça. Plano Nacional de Política Criminal e Penitenciária. Brasília: Ministério da Justiça, 2015.

. Ministério da Saúde. Pesquisa Nacional sobre População em Situação de Rua. Brasília: Ministério da Justiça, 2008.

. Ministério da Saúde. Caminhos do cuidado/Formação em saúde mental (crack, álcool e outras drogas. Brasília: Ministério da Saúde, 2015.

- Ministério da Justiça e Segurança Pública. Levantamento nacional de informaçôes penitenciárias INFOPEN-Atualização Junho/2016. Brasília: Ministério da Justiça e Segurança Pública, 2017a.

. Ministério da Saúde. Resoluçâo no 32, de 14 de dezembro de 2017. Brasília: Ministério da Saúde, 2017b.

. Ministério da Saúde. Decreto no 9.761, de 11 de abril de 2019. Brasília: Ministério da Saúde, 2019.

CARDOSO, A. O. G; BECKER, M. A. A. Identificando adolescentes em situação de rua com potencial para altas habilidades/superdotação. Rev.bras.educ.espec., v. 20, n. 4, p. 605-614, 2014.

CERQUEIRA, D. et al. Atlas da Violência 2017. Rio de Janeiro: IPEA/FBSP, 2017.

COSTA, G. M. C. et al. A saúde dos detentos sob a responsabilidade das equipes de Saúde da Família: realidade e possibilidades. Rev. APS, v. 17, n. 1, p. 76-84, 2014.

COSTA, S. L.et al. Gestantes em situação de rua no município de Santos, SP: reflexôes e desafios para as políticas públicas. Saude soc., São Paulo, v. 24, n. 3, p. 1089-1102, set. 2015.

COSTA, P. H. A; RONZANI, T. M; COLUGNATI, F. A. B. "No papel é bonito, mas na prática...”. Análise sobre a rede de atenção aos usuários de drogas nas políticas e instrumentos normativos da área. Saude soc., São Paulo, v. 26, n. 3, p. 738-750, set. 2017.

FOUCAUlT, M. História da Loucura na Idade Clássica. São Paulo: Perspectiva, 1978.

FIORE, M. O lugar do Estado na questão das drogas: o paradigma proibicionista e as alternativas. Novos Estud. - CEBRAP, São Paulo, n. 92, p. 9-21, mar. 2012.

GABATZ, R. I. B. et al. Percepção dos usuários de crack em relação ao uso e tratamento. Rev. Gaúcha Enferm., Porto Alegre, v. 34, n. 1, p. 140-146, mar. 2013. 
GOFFMAN, E. Estigma - Notas sobre a manipulação da identidade deteriorada. Tradução de Márcia Bandeira de Mello Leite Nunes. 4.ed, Rio de Janeiro: LTC,2017.

. Manicômios, prisóes e conventos. Tradução Dante Moreira Leite. 9. ed São Paulo: Perspectiva, 2015.

KAMI, M. T. M. et al. Trabalho no consultório na rua: uso do software IRAMUTEQ no apoio à pesquisa qualitativa. Rev. Esc. Anna Nery, Rio de Janeiro, v. 20, n. 3, e20160069, 2016.

KERSTENETZKY, C. L. Welfare State e desenvolvimento. Rev. De Ciências Sociais, Rio de Janeiro, v.54,n1,p.129-156, 2011.

JORGE, K. O. et al. Influência do grupo de pares e uso de drogas ilícitas entre adolescentes brasileiros: um estudo transversal. Cad. Saúde Pública, Rio de Janeiro, v. 34, n. 3, e00144316, 2018.

LERMEN, H.S.; DATORA, S.; CAPRA-RAMOS, C. Drogadição no cárcere: questôes acerca de um projeto de desintoxicação de drogas para pessoas privadas de liberdade. Estudos e Pesquisas em Psicologia, Rio de Janeiro, v. 14, n. 2, p. 539-559, 2014.

MOMBELli, M. A.; MARCON, S. S.; COSTA, J. B. Caracterização das internaçóes psiquiátricas para desintoxicação de adolescentes dependentes químicos. RevBrasEnferm, v. 63, n. 5, p. 735-740, 2010.

NICOLAU, A. I. O. et al. Retrato da realidade socioeconômica e sexual de mulheres presidiárias. Acta Paul Enferm., v. 25, n. 3, p. 386-92, 2012.

NETO, J. A. B. et al. Figuras e facetas da lógica proibicionista-medicalizante nas políticas sobre drogas, no Brasil. Rev. Polis e Psique, v. 6, n. 3, p. 59-76, 2016.

OLIVEIRA, L. V. et al. Perfil epidemiológico de presidiárias no estado da Paraíba-Brasil: um estudo descritivo. Onlinebrazj nurs., v. 12, n. 4, p. 892-901, 2013. Disponível em: http://www. objnursing.uff.br/index.php/nursing/article/view/4284

PAIVA, I. K. S. et al. Direito à saúde da população em situação de rua: reflexôes sobre a problemática. Ciênc. saúde coletiva, Rio de Janeiro, v. 21, n. 8, p. 2595-2606, ago. 2016.

PENIDO, C. M. F. Apoio matricial em saúde mental no contexto da saúde coletiva. In:

Saúde mental na atenção básica. Porto Alegre: Sulina, 2013. p. 287-300.

PEREIRA, M. O. et al. What is the emphasis of Brazilian drug policy: resocialization or internment? Esc. Anna Nery, Rio de Janeiro, v. 21, n. 3, e20170044, 2017. Disponível em: $<$ http://www.scielo.br/scielo.php?script=sci_arttext\&pid=S1414-81452017000300212\&lng=en $\& \mathrm{nrm}=\mathrm{iso}>$

PETUCO, D. R. S. Ex-viciado conta que a maioria dos amigos que consumia crack já morreu. In: ______. Descriminalizaçâo do cuidado: políticas, cenários e experiências em redução de danos. Porto Alegre: Rede Multicêntrica, 2017. p. 111-132. 
RAUPP, L.; ADORNO, R. C. F. Territórios psicotrópicos na região central da cidade de Porto Alegre, RS, Brasil. Saude soc., São Paulo, v. 24, n. 3, p. 803-815, set. 2015.

RYBCA, L. N.; NASCIMENTO, J. L. do; GUZZO, R. S. L. Os mortos e feridos na "guerra às drogas": uma crítica ao paradigma proibicionista. Estud. psicol., Campinas, v. 35, n. 1, p. 99109, mar. 2018.

SANTOS, G.; QUEIROZ, I. S. Internação psiquiátrica compulsória de usuários abusivos de drogas: uma falência ao SUS e um desuso da Política de Redução de Danos. Rev. Saúde Pública do SUS, Belo Horizonte, v. 4, n. 1, p. 59-69, 2016.

SOUZA, T. P.; CARVALHO, S. R. Apoio territorial e equipe multirreferencial: cartografias do encontro entre o apoio institucional e a redução de danos nas ruas e redes de Campinas, SP, Brasil. Interface (Botucatu), v. 18, supl. 1, p. 945-956, Dec. 2014.

TAKAHARA, A. H. et al. Relaçóes familiares, álcool e outras drogas: uma revisão integrativa. Rev. APS, v. 20, n.3, p. 434-443, 2017.

TEIXEIRA, M. B. et al. Tensões paradigmáticas nas políticas públicas sobre drogas: análise da legislação brasileira no período de 2000 a 2016. Ciênc. saúde coletiva, Rio de Janeiro, v. 22, n. 5, p. 1455-1466, maio 2017.

TORCATO, C. E. M.; RIBEIRO, T. M. Governamentalidades e usos de drogas no Brasil. Argumentum, Vitória, v. 7, n. 1, p. 39-54, jan.-jun. 2015.

UNITED NATIONS OFFICE ON DRUGS AND CRIME. Relatório Mundial sobre Drogas. Viena, 2017.

VARGAS, A. de F. M.; CAMPOS, M. M. A trajetória das políticas de saúde mental e de álcool e outras drogas no século XX. Ciênc. saúde coletiva, Rio de Janeiro, v. 24, n. 3, p. 1041-1050, mar. 2019.

WACQUANT, L. Marginalidade, etnicidade e penalidade na cidade neoliberal Uma cartografia analítica. Tempo Social, revista de sociologia da USP, v. 26, n. 2, p. 139-164, 2014.

ZUIM, R. C. B.; TRAJMAN, A. Itinerário terapêutico de doentes com tuberculose vivendo em situação de rua no Rio de Janeiro. Physis, Rio de Janeiro, v. 28, n. 2, e280205, 2018.

\section{Nota}

${ }^{1}$ L. V. e Oliveira trabalhou na concepção do estudo, na pesquisa teórica e na redação do artigo. A. A. Coelho, P. T. C. de O. Salvador e C. H. S. de M. Freitas trabalharam na redação e na revisão crítica do conteúdo intelectual. 


\section{Abstract}

\section{Visible and invisible walls: reflections on the itinerary of drug users in Brazil}

This theoretical essay aims to contribute to the debate on care for drug users in Brazil. Thus, it problematizes the prohibitionist and segregating approach historically offered to this population and proposes discussion on drug use from the perspective of health and the social / legal sciences. In addition, it analyzes the itinerary of drug users, who end up occupying "permanently" and cyclically public spaces that corroborate the worsening of their life and illness trajectory, causing a direct burden on themselves and their families, enhancing segregation and redesigning asylums, prisons and streets. Some sociological and anthropological contributions by Erving Goffman are revisited, which offer interpretation keys for understanding the stigmas that permeate drug users, especially after their inclusion in total institutions. The proposed reflections underscore the need to consolidate harm reduction strategies as an integral and ethical care tool for this clientele.

Keywords: drug users; prisons; psychiatric hospitals; street population. 